\title{
Serum folate concentration and health-related quality of life among the elderly in South Korea
}

\author{
Eunmi Lee and Sangshin Park ${ }^{*}$ (D)
}

\begin{abstract}
Background: The purpose of this study was to investigate the association between serum folate concentration and health-related quality of life (HRQOL) among the elderly in South Korea.

Materials and methods: The data used in this study were drawn from 1,021 participants over 65 years old in the Korea National Health and Nutrition Examination Survey from 2016-2018. HRQOL was measured by the EQ-5D questionnaire. Participants were divided into tertiles of folate concentration (ranges 1.7-5.6, 5.7-9.4, and 9.5-31.9 ng/mL). We performed multivariable linear regression to examine the relationship between folate and HRQOL, and multivariable logistic regression to examine the relationship between folate and the dimensional problem of HRQOL.

Results: Higher folate concentrations were significantly associated with higher HRQOL in the elderly. The average HRQOL score of the elderly in the highest tertile of the folate level was 0.0289 higher than that of the lowest tertile (coefficient: $0.0289 ; 95 \% \mathrm{Cl} 0.0016,0.0563$ ). The HRQOL score increased by 0.0174 points when the folate concentration increased by $100 \%$. When analyzing specific dimensions, a significant association with folate concentration was found only for the self-care dimension of HRQOL (odds ratio for self-care problems: $0.63 ; 95 \% \mathrm{Cl} 0.41,0.99$ ).
\end{abstract}

Conclusions: The elderly with higher serum folate concentration tended to have higher HRQOL. Among HRQOL dimensions, self-care was only significantly associated with folate concentration.

Keywords: Folate, Folic acid, Health-related quality of life, Elderly

\section{Introduction}

Recently, an increasing number of studies have focused on health-related quality of life (HRQOL) as its importance has grown [1-3]. Testa et al. [4] and McDonald et al. [5] proposed that HRQOL is a multidimensional concept that includes areas related to physical, mental, emotional and social functions. The authors of the latter study also emphasized that HRQOL focuses on the impact of an individual's health status on their quality of life [5]. The fact that HRQOL is affected by diseases

${ }^{*}$ Correspondence: dvm.spark@gmail.com

Graduate School of Urban Public Health \& Department of Urban Big Data Convergence, University of Seoul, 163 Seoulsiripdae-ro, Dongdaemun-gu, Seoul 02504, Republic of Korea such as obesity [6], hypertension [3, 7], and diabetes [8] has already been proven through multiple studies. As the importance of HRQOL has increased, the development of HRQOL has become one of the primary purposes of public health research [9].

The EQ-5D is one of the most used HRQOL measurement tools. The EQ-5D consists of five dimensions (mobility, self-care, usual activities, pain/discomfort, and anxiety/depression). The EQ-5D-3L is designed to let participants choose one of the three levels (e.g., no, some, or severe problem) based on the severity of each dimension. The EQ-5D-5L is an updated version of the EQ-5D-3L which includes five severity levels (e.g., no problems to extreme problems/unable to). The EQ-5D-Y assesses HRQOL of children and adolescents. Of each original author(s) and the source, provide a link to the Creative Commons licence, and indicate if changes were made. The images or other third party material in this article are included in the article's Creative Commons licence, unless indicated otherwise in a credit line to the material. If material is not included in the article's Creative Commons licence and your intended use is not permitted by statutory regulation or exceeds the permitted use, you will need to obtain permission directly from the copyright holder. To view a copy of this licence, visit http://creativecommons.org/licenses/by/4.0/. The Creative Commons Public Domain Dedication waiver (http://creativeco mmons.org/publicdomain/zero/1.0/) applies to the data made available in this article, unless otherwise stated in a credit line to the data. 
version of EQ-5D, the EQ-VAS assesses self-rated health on a vertical scale from zero to 100 , which means worst to best health imaginable. In the EQ-5D, severity levels in five dimensions are converted into a single score by applying a formula [10].

The nutrition status of the elderly is of grave importance as it is related to morbidity and mortality in the elderly [11]. The effects of nutritional status on physical and psychological well-being are greater in the elderly than in other age groups [12]. A particularly important factor is folate nutrition, which is associated with various important health problems in the elderly, such as cardiovascular disease, cancer, and cognitive function [11]. Accordingly, folate insufficiency contributes to decreased HRQOL in the elderly [13].

Folate is a water-soluble vitamin that is related to the other B vitamins, and it is a key nutritional factor in general cell growth and replication [14]. The intake recommendation of folate varies by age, sex, and individual health condition, but the typical recommendation for all aged 14 or older is $400 \mu \mathrm{g}$ per day $[15,16]$. Appropriate folate intake facilitates cell division and homeostasis, which is the essential role of folate coenzymes in nucleic acid synthesis, as well as methionine regeneration; in the shuttling, the oxidation and reduction of one-carbon units is required for normal metabolism and regulation [17]. On the other hand, inappropriate intake or malabsorption of folate may lead to harmful consequences, such as increased risk of chronic diseases and developmental disorders [17].

Numerous studies have been published on the relationship between folate levels and chronic diseases [18, 19]. For example, patients with rheumatoid arthritis had decreased cardiovascular mortality risks when their serum folate levels were at least $4.3 \mathrm{ng} / \mathrm{mL}$ [18]. Lower serum folate levels were associated with higher all-cause, cardiovascular, and cancer mortalities [19]. However, only few studies reported the relationship between folate levels and chronic diseases or conditions in South Korea $[20,21]$. For example, the Korean elderly whose serum folate levels were declined from $>8.2 \mathrm{ng} / \mathrm{mL}$ to $\leq 5.9 \mathrm{ng} /$ $\mathrm{mL}$ had 2.4 times higher risks for dementia than those with maintaining serum folate levels $>8.2 \mathrm{ng} / \mathrm{mL}$ during the 4-year follow-up period [20]. Another study showed the negative association between serum folate levels and body mass index (BMI) at mid- and late pregnancy in Korea [21].

Aging is one of the major causes of decreasing HRQOL, specifically due to factors such as biological senility and socio-psychological variations [22]. Diseases such as Alzheimer's disease and rheumatoid arthritis, which are particularly common in the elderly, have been proven in many studies to significantly decrease the HRQOL of the individuals with such diseases [23, 24]. These diseases reduce HRQOL by causing physical discomfort, while depression reduces HRQOL due to the associated mental and emotional problems [25]. Although many studies have examined the relationship between folate and various diseases that significantly reduce HRQOL [26-30], no studies have investigated the relationship between folate and HRQOL.

As we have seen, HRQOL is increasingly becoming important in relation to the health of an individual. Based on the existing research on the relationship between folate and various diseases, we conducted this study beginning with the hypothesis that a higher folate concentration is associated with a higher HRQOL. Therefore, this study was performed to examine the relationship between folate and HRQOL among the elderly using national representative sampling data.

\section{Methods}

\section{Study area and design}

This study was performed using the data obtained from the Korea National Health and Nutrition Examination Survey (KNHANES) conducted from 2016 to 2018 (https://knhanes.cdc.go.kr/knhanes/sub03/sub03_02_05. do). The KNHANES has been conducted by the Korean Centers for Disease Control and Prevention (KCDC) since 1998 to evaluate the health and nutritional status of Koreans. The survey has been widely accepted for its efficiency for use in statistical analyses of the health and nutrition status of Korean citizens.

The KNHANES consists of three surveys: a health examination, a health interview, and a nutrition survey. The health examination includes body measurement, blood pressure and pulse measurement, blood and urine test, oral examination, pulmonary function test, eye test, and grip test. The health interview consists of household and individual interviews. The household interview is administered to one adult (over 19 years old) of the household to assess the number of household members, household types, and household income. The individual interview is administered to each member of the household to assess morbidity, healthcare utilization, activity restriction, education and economic activities, physical activities, as well as smoking, drinking, mental health, safety consciousness, and oral health. The nutrition survey is conducted to evaluate the status of dietary behavior, dietary supplements, nutritional knowledge, food stability, and the contents of food intake one day before the survey. 


\section{Sampling}

The target population of the KNHANES was extracted using the two-step stratified cluster sampling, so that the representativeness of the Korean population could be obtained. Participants of KNHANES were drawn from 576 locations and approximately 13,000 households in each wave over the 3-year period (i.e., 192 locations and 3,840 households annually). For sampling, KNHANES stratified Korean population according to city/province (Seoul, Busan, Daegu, Incheon, Gwangju, Daejeon, Ulsan, Sejong, Gyeonggi, Gangwon, Chungbuk, Chungnam, Jeonbuk, Jeonnam, Gyeongbuk, Gyeongnam, and Jeju), dong/eup/myeon, and home types. They considered ratios of residential area and education level of head of household for sampling. Of 24,269 participants of KNHANES 2016-2018, our study used the data of 1021 participants who were aged 65 years or older, who completed the EQ-5D questionnaire, and who were measured for serum folate levels.

\section{Data collection instrument, process, and management}

Blood samples were collected in the morning with overnight fast. Serum folate levels, our independent variable of interest, were measured through Chemiluminescent Microparticle Immunoassay (ARCHITECT i4000Sr; Abbott, Abbott Park, IL).

KNHANES measured HRQOL, our dependent variable of interest, using EQ-5D questionnaire. The elderly was surveyed on EQ-5D through face-to-face interviews. The EQ-5D consists of five dimensions (mobility, self-care, usual activities, pain/discomfort, and anxiety/depression). Each dimension has three health status levels meaning no problem, some problem, and a severe problem. The EQ-5D score was derived by combining all scores for the five dimensions, which ranged from 0 to $1 ; 0$ indicating death and 1 indicating perfect health state. The score less than 0 means health state worse than death. The EQ-5D score was estimated through N3 model [31].

\section{Operational definitions}

Marital status was divided into two categories: 'married and living together' and the others. Education level was divided into three categories: $\leq$ middle school, high school, and $\geq$ college. Employment status was divided into two categories: employed and unemployed. Household income was divided into quartiles: low-, lower-middle-, upper-middle-, and high-income groups. A current smoker was defined as a person who had smoked more than five packs of cigarettes and who were currently smoking. An alcohol consumer was defined as a person who had drunk at least once a month within a year.
Performing aerobic physical activity was defined as moderate aerobic physical activity $\geq 150 \mathrm{~min} /$ week or intense aerobic physical activity $\geq 75 \mathrm{~min} /$ week.

BMI was calculated as body mass divided by the square of the body height, with body mass in kilograms and body height in meters. Diabetes mellitus was defined as fasting blood sugar $\geq 126 \mathrm{mg} / \mathrm{dL}$, taking a medicine/insulin, or having been diagnosed by a doctor. Hypertension was defined as systolic blood pressure of $140 \mathrm{mmHg}$ or higher, diastolic blood pressure of $90 \mathrm{mmHg}$ or higher, or taking a relevant medicine. An individual was classified as having dyslipidemia if he or she met any of the following criteria: fasting triglyceride $\geq 200 \mathrm{mg} / \mathrm{dL}$, highdensity lipoprotein cholesterol $<40 \mathrm{mg} / \mathrm{dL}$, total cholesterol $\geq 240 \mathrm{mg} / \mathrm{dL}$, or taking any dyslipidemia medicine.

\section{Data entry, analysis, and interpretation}

All analyses were conducted using SAS software version 9.4 (SAS Institute Inc., Cary, NC, USA) while accounting for the sampling design of complex surveys. The independent and dependent variables of interest were serum folate levels and HRQOL, respectively. We performed multivariable linear regression to analyze the relationship between folate levels and HRQOL. Model 1 examined the relationship between folate levels and HRQOL without adjustment. In model 2, we adjusted for age and sex; in model 3, we further adjusted for marital status, education level, employment status, household income, current smoking, alcohol consumption, aerobic physical activity, and BMI; and in model 4, we further adjusted for diabetes mellitus, hypertension, and dyslipidemia.

We also performed multivariable logistic regression analysis to evaluate the relationship between serum folate levels and the dimensional problem (some or severe problem) of EQ-5D. Throughout the analysis, the $\mathrm{p}$ value $<0.05$ was regarded as statistically significant. The folate level values were log-transformed. We then used log-transformed folate levels as independent variables in both linear and logistic regression models.

\section{Results}

The mean age of the participants in this study was 72.5 years (range $65-80$ years). The participants in each folate level group of T1 (1.7-5.6), T2 (5.7-9.4), and T3 (9.5-31.9) represented 33.2\% $(\mathrm{n}=339), 34.1 \%(\mathrm{n}=348)$, and $32.7 \%(\mathrm{n}=334)$ of all subjects, respectively (Table 1$)$. The mean ages of the participants in T1, T2, and T3 were 73.2, 72.4, and 72.7 years, respectively. As the folate level increased, the percentage of females, participation in aerobic physical activity, pain/discomfort problems, and HRQOL increased, while the percentage of marital status (married and living together), current smoking, alcohol consumption, diabetes mellitus, mobility, and 
Table 1 Basic characteristics of the study participants by folate level

\begin{tabular}{|c|c|c|c|c|}
\hline \multirow[t]{2}{*}{ Characteristic } & \multicolumn{3}{|c|}{ Tertiles of folate level (range, $\mathrm{ng} / \mathrm{mL}$ ) } & \multirow[t]{2}{*}{$P$} \\
\hline & $\mathrm{T} 1(4.3,1.7-5.6)$ & $\mathrm{T} 2(7.1,5.7-9.4)$ & T3 $(12.4,9.5-31.9)$ & \\
\hline Participants, n & 339 & 348 & 334 & \\
\hline Age, years & $73.2(0.4)$ & $72.4(0.3)$ & $72.7(0.3)$ & 0.20 \\
\hline Female, \% & $38.3(3.1)$ & $53.9(3.0)$ & $67.2(2.8)$ & $<0.001$ \\
\hline Marital status (married \& living together), \% & $66.5(3.0)$ & $66.3(3.1)$ & $61.3(3.3)$ & 0.40 \\
\hline \multicolumn{5}{|l|}{ Socioeconomic status variables } \\
\hline Education level, \% & & & & 0.039 \\
\hline$\leq$ Middle school & $70.1(3.0)$ & $73.3(2.8)$ & $64.7(3.3)$ & \\
\hline High school & $19.6(2.5)$ & $18.9(2.5)$ & $18.9(2.6)$ & \\
\hline$\geq$ College & $10.4(2.0)$ & $7.7(1.6)$ & $16.5(2.3)$ & \\
\hline Employment status, \% & & & & 0.002 \\
\hline Employed & $29.7(2.9)$ & $37.8(3.2)$ & $23.5(2.6)$ & \\
\hline Unemployed & $70.3(2.9)$ & $62.2(3.2)$ & $76.5(2.6)$ & \\
\hline Household income, \% & & & & 0.12 \\
\hline Low & $47.2(3.5)$ & $46.4(3.4)$ & $43.8(3.3)$ & \\
\hline Lower middle & $27.9(3.1)$ & $27.6(3.0)$ & $23.1(2.5)$ & \\
\hline Upper middle & $17.6(2.8)$ & $16.1(2.5)$ & $17.5(2.5)$ & \\
\hline High & $7.3(1.6)$ & $9.9(1.9)$ & $15.7(2.4)$ & \\
\hline \multicolumn{5}{|l|}{ Lifestyle variables } \\
\hline Current smoking, \% & $15.5(2.2)$ & $6.7(1.7)$ & $4.9(1.3)$ & $<0.001$ \\
\hline Alcohol consumption ( $\geq 1 \mathrm{drink} /$ month), $\%$ & $42.6(3.2)$ & $36.6(2.9)$ & $26.8(2.6)$ & 0.001 \\
\hline Aerobic physical activity, $\%$ & $27.1(2.8)$ & $32.5(2.9)$ & $37.4(3.1)$ & 0.040 \\
\hline \multicolumn{5}{|l|}{ Disease variables } \\
\hline BMI, mean & $23.9(0.2)$ & $24.2(0.2)$ & $24.0(0.2)$ & 0.53 \\
\hline Diabetes mellitus, $\%$ & $30.2(3.2)$ & $26.4(2.7)$ & $23.8(2.6)$ & 0.30 \\
\hline Hypertension, \% & $68.1(2.7)$ & $62.2(3.2)$ & $62.8(3.0)$ & 0.30 \\
\hline Dyslipidemia, \% & $55.1(3.2)$ & $54.3(3.0)$ & $57.7(3.1)$ & 0.73 \\
\hline HRQOL (score of EQ-5D) & $0.866(0.01)$ & $0.877(0.01)$ & $0.887(0.01)$ & 0.30 \\
\hline \multicolumn{5}{|l|}{ Problem in dimensions, $\%$} \\
\hline Mobility & $40.4(3.2)$ & $37.2(3.3)$ & $34.7(3.2)$ & 0.44 \\
\hline Self-care & $14.2(2.2)$ & $10.2(1.9)$ & $8.5(1.6)$ & 0.09 \\
\hline Usual activities & $22.3(2.4)$ & $21.7(2.9)$ & $22.2(2.6)$ & 1.00 \\
\hline Pain/discomfort & $36.9(3.2)$ & $37.0(3.2)$ & $38.4(3.0)$ & 0.94 \\
\hline Anxiety/depression & $15.8(2.5)$ & $17.6(2.4)$ & $15.2(2.0)$ & 0.74 \\
\hline
\end{tabular}

self-care problems decreased. The increase in folate levels was not significantly associated with age, education level, employment status, household income, BMI, hypertension, dyslipidemia, usual activities, or anxiety/depression problems.

The HRQOL scores were 0.880 (T1), 0.892 (T2), and 0.909 (T3) at each level of folate concentration after adjusting for all confounding variables (Fig. 1).

In adjusted models, HRQOL was also significantly associated with folate concentration (Table 2). After adjusting for age and sex, the HRQOL score of T3 was 0.0399 higher than that of T1 [Model 2; coefficient: 0.0399; 95\% confidence interval (CI) 0.0122, 0.0676; p for trend: 0.005]. For Model 4, diabetes mellitus, hypertension, and dyslipidemia were added to Model 3 to test the outcomes after controlling for all variables. As a result, the HRQOL score of T3 was 0.0289 higher than that of T1 [Model 4; coefficient: 0.0289 ; 95\% CI 0.0016, 0.0563; p for trend: 0.038].

A significant relationship between folate and HRQOL was found when analyzing folate concentration as a continuous variable [coefficient: 0.0251; 95\% CI 0.0018, 0.0483; p value: 0.035] (Table 3). When the folate concentration increased by $100 \%$, the HRQOL score increased by 0.0174 points (coefficient $0.0251 \times \ln (2)=0.0174)$. 


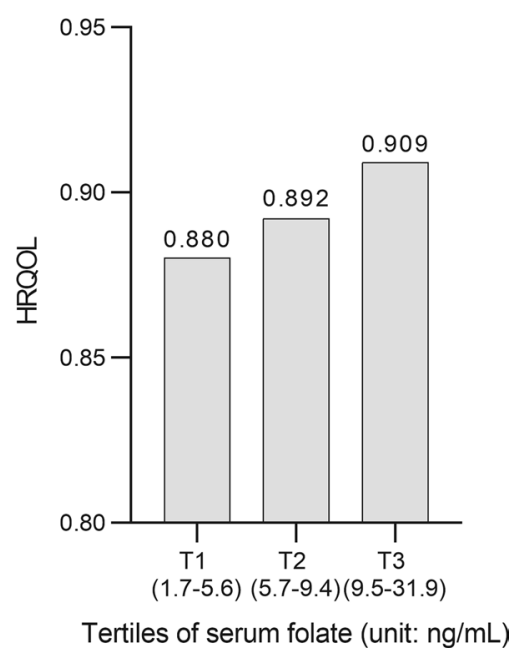

Fig. 1 The HRQOL scores by folate level after adjusting for age, sex, marital status, education level, employment status, household income, smoking, alcohol consumption, aerobic physical activity, BMI, diabetes mellitus, hypertension, and dyslipidemia

When HRQOL was examined according to each dimension, folate concentration was particularly related to self-care problems (Table 4). The odds ratio of self-care problems and folate concentration in Model 4 is 0.63 (OR 0.63; 95\% CI 0.41, 0.99). When the folate concentration increased by $100 \%$, the selfcare problem decreased by approximately $27 \%$ (exp (ln $(0.63) \times \ln (2))=0.73)$.

\section{Discussion}

To date, no study has examined the relationship between folate and HRQOL. This study showed that folate and HRQOL are related; specifically, the higher serum folate concentration has the higher HRQOL. The increase in the score of HRQOL as folate concentration increased was significant in the model that adjusted several variables. Among the EQ-5D dimensions, folate concentration was most related to self-care problems. As
Table 3 Coefficient $(95 \% \mathrm{Cl})$ of HRQOL and folate concentration

\begin{tabular}{llc}
\hline Model & Coefficient $(\mathbf{9 5 \%} \mathrm{Cl})$ & P value \\
\hline 1 & $0.0202(-0.0026,0.0429)$ & 0.082 \\
2 & $0.0338(0.0104,0.0571)$ & 0.005 \\
3 & $0.0253(0.0021,0.0485)$ & 0.033 \\
4 & $0.0251(0.0018,0.0483)$ & 0.035 \\
\hline Model 1: not adjusted; Model 2: adjusted for age and sex; Model 3: further \\
adjusted for marital status, education level, employment status, household \\
income, smoking, alcohol consumption, aerobic physical activity, and BMl; \\
\multicolumn{2}{l}{ Model 4: further adjusted for diabetes mellitus, hypertension, and dyslipidemia }
\end{tabular}

folate concentration increased, self-care problems significantly decreased.

Many studies have demonstrated relationships between folate and various diseases, such as obesity [32], hypertension [33], and diabetes [34]. In addition, several studies have already proven that such chronic diseases are associated with a decrease in HRQOL [3, 6-8]. Thus, we were interested in the relationship between folate and HRQOL among the elderly, and we had a strong expectation that there would be a positive relationship between folate and HRQOL.

The mechanisms governing the relationship between folate intake and HRQOL are unclear. However, considering that studies have shown that high folate intake lowers the incidence of various diseases and that patients with such diseases have lower HRQOL, it can be expected that increased serum folate levels may improve HRQOL.

Several studies have supported the hypothesis that folate intake could act as a protective factor against obesity [32, 35, 36]. Further, studies have shown significant associations between serum folate, DNA methylation, BMI, body fat ratio [37], and high folate intake from fortified foods with high DNA methylation [35, 38]. The methionine cycle is a metabolic process by which methionine becomes homocysteine via S-Adenosylhomocystein and S-Adenosylmethionine, and then homocysteine is converted back into methionine by recovering the methyl group from the folate cycle [39]. The types of nutrition

Table 2 Coefficient $(95 \% \mathrm{Cl}$ ) of HRQOL by folate concentration

\begin{tabular}{|c|c|c|c|c|}
\hline & \multicolumn{3}{|c|}{ Tertiles of folate level (median, range, $\mathrm{ng} / \mathrm{mL}$ ) } & \multirow[t]{2}{*}{$P$ for trend } \\
\hline & $\mathrm{T} 1(4.3,1.7-5.6)$ & $\mathrm{T} 2(7.1,5.7-9.4)$ & T3 $(12.4,9.5-31.9)$ & \\
\hline Participants, n & 339 & 348 & 334 & \\
\hline Model 1 & Reference & $0.0117(-0.0195,0.0428)$ & $0.0219(-0.0060,0.0499)$ & 0.12 \\
\hline Model 2 & Reference & $0.0177(-0.0103,0.0457)$ & $0.0399(0.0122,0.0676)$ & 0.005 \\
\hline Model 3 & Reference & $0.0120(-0.0148,0.0389)$ & $0.0295(0.0021,0.0569)$ & 0.035 \\
\hline Model 4 & Reference & $0.0118(-0.0148,0.0385)$ & $0.0289(0.0016,0.0563)$ & 0.038 \\
\hline
\end{tabular}

Model 1: not adjusted; Model 2: adjusted for age and sex; Model 3: further adjusted for marital status, education level, employment status, household income, smoking, alcohol consumption, aerobic physical activity, and BMl; Model 4: further adjusted for diabetes mellitus, hypertension, and dyslipidemia 
Table 4 Odds ratios (95\% Cl) of HRQOL dimensional problems and folate concentration

\begin{tabular}{llllll}
\hline Model & Mobility & Self-care & Usual activities & Pain/discomfort & Anxiety/depression \\
\hline 1 & $0.83(0.62,1.11)$ & $0.58(0.39,0.85)^{* *}$ & $0.97(0.71,1.32)$ & $1.02(0.76,1.39)$ & $0.97(0.68,1.40)$ \\
2 & $0.71(0.51,0.99)^{*}$ & $0.55(0.37,0.84)^{* *}$ & $0.87(0.62,1.22)$ & $0.81(0.58,1.13)$ & $0.88(0.61,1.28)$ \\
3 & $0.80(0.56,1.14)$ & $0.63(0.40,0.98)^{*}$ & $0.99(0.69,1.44)$ & $0.88(0.62,1.24)$ & $0.87(0.59,1.29)$ \\
4 & $0.79(0.56,1.13)$ & $0.63(0.41,0.99)^{*}$ & $1.00(0.69,1.45)$ & $0.88(0.62,1.24)$ & $0.88(0.59,1.30)$
\end{tabular}

Model 1: not adjusted; Model 2: adjusted for age and sex; Model 3: further adjusted for marital status, education level, employment status, household income, smoking, alcohol consumption, aerobic physical activity, and BMI; Model 4: further adjusted for diabetes mellitus, hypertension, and dyslipidemia. * $p<0.05,{ }^{* *} p<0.01$, *** $\mathrm{p}<0.001$

deficiency that can lead to damage to homocysteine metabolism include folate deficiency, which increases the concentration of plasma homocysteine [40]. As a result, high homocysteine may serve as a risk factor for obesity [41]. Therefore, adequate levels of folate in the blood do not increase homocysteine levels, which may help prevent obesity.

Similarly, it is speculated that adequate levels of folate in the blood may lower risks of hypertension by lowering the homocysteine levels. Hyperhomocysteinemia is responsible for hypertension by increasing oxidative stress [42-45]. Increased homocysteine in plasma causes oxidative stress and endothelial dysfunction, leading to vasoconstriction, vasodilation by nitric acid, and nitrate reduction, all of which increase blood pressure [42, 44]. A high homocysteine level, also called hyperhomocysteinemia, is known to be regulated through the intake of grain fortification foods containing folate [46] and folic acid supplements [47]. In a recent meta-analysis study of randomized experiments, folate intake has been proven to be effective in reducing blood pressure and homocysteine levels among patients with hypertension and hyperhomocysteinemia [42, 48].

Our study showed that serum folate concentration was associated with self-care problems. Low folate concentration was likely to affect self-care problems through sarcopenia. Previous studies showed the relationship between low intakes of folate and the risk of sarcopenia [49] and the relationship between the sarcopenia and the impairment in self-care [50].

This is the first study to examine the specific relationship between folate and HRQOL. While there have been studies investigating the relationship between folate and diseases [32-34] or diseases and HRQOL [3, 6-8], there have been no studies examining the relationship between folate and HRQOL. Another strength is that this study was conducted using national representative sample data. These data were obtained from KNHANES, which indicates that the study participants are representative of the Korean population. Therefore, the results of this study can be generalized to the entire population. However, because the results of this study rely on the cross-sectional study of KNHANES, it has a limitation in that it cannot clearly elucidate the causal relationship between folate and HRQOL.

\section{Conclusions}

Increased levels of serum folate were associated with increased HRQOL and decreased problems in self-care dimension of HRQOL in the Korean elderly. Our findings suggest that maintaining adequate levels of serum folate is possibly helpful in improving HRQOL in the elderly. Further prospective studies are required to confirm the causality that increased levels of serum folate improves HRQOL.

\section{Acknowledgements \\ Not applicable.}

\section{Authors' contributions}

EL contributed to the design of the work, acquisition of data and analysis, interpretation of data, and writing initial manuscript. SP contributed to the design of the work and interpretation of data and has substantively revised the manuscript. All authors reviewed the manuscript and approved the submission of the manuscript. All authors read and approved the final manuscript.

\section{Funding}

No funding was received for this study.

\section{Availability of data and materials}

The datasets are available in the Korea Centers for Disease Control and Prevention (https://knhanes.cdc.go.kr/knhanes).

\section{Declarations}

Ethics approval and consent to participate Informed consent was obtained from all individual participants included in the study. This study was approved for exemption from the institutional ethical review board at the University of Seoul (IRB No. 2020-11-008).

\section{Consent for publication}

Not applicable.

\section{Competing interests}

The authors declare that they have no competing interests.

Received: 8 August 2021 Accepted: 29 November 2021

Published online: 20 December 2021 


\section{References}

1. Allen PF. Assessment of oral health related quality of life. Health Qual Life Outcomes. 2003:1:40.

2. Gift HC, Atchison KA. Oral health, health, and health-related quality of life. Med Care. 1995;33:NS57-77.

3. Bardage C, Isacson DG. Hypertension and health-related quality of life. An epidemiological study in Sweden. J Clin Epidemiol. 2001;54:172-81.

4. Testa MA, Simonson DC. Assessment of quality-of-life outcomes. N Engl J Med. 1996:334:835-40.

5. McDonald VM, Hiles SA, Jones KA, Clark VL, Yorke J. Health-related quality of life burden in severe asthma. Med J Aust. 2018;209:S28-33.

6. Fontaine KR, Barofsky I. Obesity and health-related quality of life. Obes Rev. 2001;2:173-82.

7. Trevisol DJ, Moreira LB, Kerkhoff A, Fuchs SC, Fuchs FD. Health-related quality of life and hypertension: a systematic review and meta-analysis of observational studies. J Hypertens. 2011;29:179-88.

8. Solli O, Stavem K, Kristiansen IS. Health-related quality of life in diabetes: the associations of complications with EQ-5D scores. Health Qual Life Outcomes. 2010;8:18.

9. Testa MA, Nackley JF. Methods for quality-of-life studies. Annu Rev Public Health. 1994;15:535-59.

10. Park S. Pathways linking obesity to health-related quality of life. Qual Life Res. 2017;26:2209-18.

11. Rampersaud GC, Kauwell GP, Bailey LB. Folate: a key to optimizing health and reducing disease risk in the elderly. J Am Coll Nutr. 2003;22:1-8.

12. Pirlich $M$, Lochs H. Nutrition in the elderly. Best Pract Res Clin Gastroenterol. 2001;15:869-84

13. Watson J, Lee M, Garcia-Casal MN. Consequences of inadequate intakes of vitamin A, vitamin B12, vitamin D, calcium, iron, and folate in older persons. Curr Geriatr Rep. 2018;7:103-13.

14. Kamen B. Folate and antifolate pharmacology. Semin Oncol. 1997;24:S18-30-S18-39.

15. Hiller R, Sperduto RD, Reed GF, D'Agostino RB, Wilson PW. Serum lipids and age-related lens opacities: a longitudinal investigation: the Framingham Studies. Ophthalmology. 2003;110:578-83.

16. Jacques PF, Chylack LT Jr, Hankinson SE, Khu PM, Rogers G, Friend J, Tung W, Wolfe JK, Padhye N, Willett WC, Taylor A. Long-term nutrient intake and early age-related nuclear lens opacities. Arch Ophthalmol. 2001;119:1009-19.

17. Bailey LB, Gregory JF 3rd. Folate metabolism and requirements. J Nutr 1999;129:779-82.

18. Sonawane K, Zhu Y, Chan W, Aguilar D, Deshmukh AA, SuarezAlmazor ME. association of serum folate levels with cardiovascular mortality among adults with rheumatoid arthritis. JAMA Netw Open. 2020;3:e200100.

19. Peng Y, Dong B, Wang Z. Serum folate concentrations and all-cause, cardiovascular disease and cancer mortality: a cohort study based on 1999-2010 National Health and Nutrition Examination Survey (NHANES). Int J Cardiol. 2016;219:136-42.

20. Jang S, Han JW, Shin J, Kim TH, Kwak KP, Kim K, Kim BJ, Kim SG, Kim JL, Kim $\mathrm{TH}$, et al. Normal-but-low serum folate levels and the risks for cognitive impairment. Psychiatry Investig. 2019;16:532-8.

21. Kim H, Hwang JY, Kim KN, Ha EH, Park H, Ha M, Lee KY, Hong YC, Tamura T, Chang N. Relationship between body-mass index and serum folate concentrations in pregnant women. Eur J Clin Nutr. 2012;66:136-8.

22. Ghimire S, Baral BK, Pokhrel BR, Pokhrel A, Acharya A, Amatya D, Amatya P, Mishra SR. Depression, malnutrition, and health-related quality of life among Nepali older patients. BMC Geriatr. 2018;18:191.

23. Kempen Gl, Ormel J, Brilman El, Relyveld J. Adaptive responses among Dutch elderly: the impact of eight chronic medical conditions on healthrelated quality of life. Am J Public Health. 1997;87:38-44.

24. Salaffi F, Carotti M, Gasparini S, Intorcia M, Grassi W. The health-related quality of life in rheumatoid arthritis, ankylosing spondylitis, and psoriatic arthritis: a comparison with a selected sample of healthy people. Health Qual Life Outcomes. 2009;7:25.

25. Ruo B, Rumsfeld JS, Hlatky MA, Liu H, Browner WS, Whooley MA. Depressive symptoms and health-related quality of life: the Heart and Soul Study. JAMA. 2003;290:215-21.

26. Bender A, Hagan KE, Kingston N. The association of folate and depression: a meta-analysis. J Psychiatr Res. 2017;95:9-18.
27. Petridou ET, Kousoulis AA, Michelakos T, Papathoma P, Dessypris N, Papadopoulos FC, Stefanadis C. Folate and B12 serum levels in association with depression in the aged: a systematic review and meta-analysis. Aging Ment Health. 2016;20:965-73.

28. Whittle SL, Hughes RA. Folate supplementation and methotrexate treatment in rheumatoid arthritis: a review. Rheumatology (Oxford). 2004:43:267-71.

29. Tiemeier H, van Tuijl HR, Hofman A, Meijer J, Kiliaan AJ, Breteler MM. Vitamin B12, folate, and homocysteine in depression: the Rotterdam Study. Am J Psychiatry. 2002;159:2099-101.

30. Luchsinger JA, Tang MX, Miller J, Green R, Mayeux R. Relation of higher folate intake to lower risk of Alzheimer disease in the elderly. Arch Neurol. 2007:64:86-92.

31. Lee YK, Nam HS, Chuang LH, Kim KY, Yang HK, Kwon IS, Kind P, Kweon SS, Kim YT. South Korean time trade-off values for EQ-5D health states: modeling with observed values for 101 health states. Value Health. 2009;12:1187-93.

32. Bird JK, Ronnenberg AG, Choi SW, Du F, Mason JB, Liu Z. Obesity is associated with increased red blood cell folate despite lower dietary intakes and serum concentrations. J Nutr. 2015;145:79-86.

33. Xun P, Liu K, Loria CM, Bujnowski D, Shikany JM, Schreiner PJ, Sidney S, He K. Folate intake and incidence of hypertension among American young adults: a 20-y follow-up study. Am J Clin Nutr. 2012;95:1023-30.

34. Akbari M, Tabrizi R, Lankarani KB, Heydari ST, Karamali M, Keneshlou F, Niknam K, Kolahdooz F, Asemi Z. The effects of folate supplementation on diabetes biomarkers among patients with metabolic diseases: a systematic review and meta-analysis of randomized controlled trials. Horm Metab Res. 2018;50:93-105.

35. Pereira GA, Bressan J, Oliveira FLP, Sant'Ana HMP, Pimenta AM, Lopes $\mathrm{LL}$, Hermsdorff HHM. Dietary folate intake is negatively associated with excess body weight in Brazilian graduates and postgraduates (CUME Project). Nutrients. 2019;11:66.

36. Mlodzik-Czyzewska MA, Malinowska AM, Chmurzynska A. Low folate intake and serum levels are associated with higher body mass index and abdominal fat accumulation: a case control study. Nutr J. 2020;19:53.

37. Piyathilake CJ, Badiga S, Alvarez RD, Partridge EE, Johanning GL. A lower degree of PBMC L1 methylation is associated with excess body weight and higher HOMA-IR in the presence of lower concentrations of plasma folate. PLOS ONE. 2013;8:e54544

38. Zhang FF, Santella RM, Wolff M, Kappil MA, Markowitz SB, Morabia A. White blood cell global methylation and IL-6 promoter methylation in association with diet and lifestyle risk factors in a cancer-free population. Epigenetics. 2012;7:606-14.

39. Shen W, Gao C, Cueto R, Liu L, Fu H, Shao Y, Yang WY, Fang P, Choi ET, Wu $Q$, et al. Homocysteine-methionine cycle is a metabolic sensor system controlling methylation-regulated pathological signaling. Redox Biol. 2020:28:101322.

40. Medina M, Urdiales JL, Amores-Sanchez MI. Roles of homocysteine in cell metabolism: old and new functions. Eur J Biochem. 2001;268:3871-82.

41. Huang Y, Wu K, Li H, Zhou J, Xiong D, Huang X, Li J, Liu Y, Pan Z, Mitchell DT, et al. Homocysteine level, body mass index and clinical correlates in Chinese Han patients with schizophrenia. Sci Rep. 2020;10:16119.

42. Tamura T, Kuriyama N, Koyama T, Ozaki E, Matsui D, Kadomatsu Y, Tsukamoto M, Kubo Y, Okada R, Hishida A, et al. Association between plasma levels of homocysteine, folate, and vitamin B12, and dietary folate intake and hypertension in a cross-sectional study. Sci Rep. 2020;10:18499.

43. Rodrigo R, Gonzalez J, Paoletto F. The role of oxidative stress in the pathophysiology of hypertension. Hypertens Res. 2011;34:431-40.

44. Rodrigo R, Passalacqua W, Araya J, Orellana M, Rivera G. Homocysteine and essential hypertension. J Clin Pharmacol. 2003:43:1299-306.

45. Pravenec M, Kozich V, Krijt J, Sokolova J, Zidek V, Landa V, Simakova M, Mlejnek $P$, Silhavy J, Oliyarnyk $O$, et al. Folate deficiency is associated with oxidative stress, increased blood pressure, and insulin resistance in spontaneously hypertensive rats. Am J Hypertens. 2013;26:135-40.

46. Tice JA, Ross E, Coxson PG, Rosenberg I, Weinstein MC, Hunink MG, Goldman PA, Williams L, Goldman L. Cost-effectiveness of vitamin therapy to lower plasma homocysteine levels for the prevention of coronary heart disease: effect of grain fortification and beyond. JAMA. 2001;286:936-43.

47. Brouwer IA, van Dusseldorp M, Thomas CMG, Duran M, Hautvast J, Eskes T, Steegers-Theunissen RP. Low-Dose folic acid supplementation 
decreases plasma homocysteine concentrations: a randomised trial. Indian Heart J. 2000;52:S53-58.

48. Wang WW, Wang XS, Zhang ZR, He JC, Xie CL. A meta-analysis of folic acid in combination with anti-hypertension drugs in patients with hypertension and hyperhomocysteinemia. Front Pharmacol. 2017;8:585.

49. Petermann-Rocha F, Chen M, Gray SR, Ho FK, Pell JP, Celis-Morales C. Factors associated with sarcopenia: a cross-sectional analysis using UK Biobank. Maturitas. 2020;133:60-7.

50. Sun S, Lee H, Yim HW, Won HS, Ko YH. The impact of sarcopenia on health-related quality of life in elderly people: Korean National Health and Nutrition Examination Survey. Korean J Intern Med. 2019;34:877-84.

\section{Publisher's Note}

Springer Nature remains neutral with regard to jurisdictional claims in published maps and institutional affiliations.

- fast, convenient online submission

- thorough peer review by experienced researchers in your field

- rapid publication on acceptance

- support for research data, including large and complex data types

- gold Open Access which fosters wider collaboration and increased citations

- maximum visibility for your research: over $100 \mathrm{M}$ website views per year

At $\mathrm{BMC}$, research is always in progress.

Learn more biomedcentral.com/submissions 